\title{
BIOLOGICAL ENHANCEMENTS FOR ANTERIOR CRUCIATE LIGAMENT RECONSTRUCTION
}

\author{
ESTRATÉGIAS DE TRATAMENTO BIOLÓGICO PARA CIRURGIA DE \\ RECONSTRUÇÃO DO LIGAMENTO CRUZADO ANTERIOR
}

\author{
Chilan Bou Ghosson Leite ${ }^{1}$, Marco Kawamura Demange ${ }^{1}$ \\ 1. Universidade de São Paulo, Hospital das Clínicas, HCFMUSP, Faculdade de Medicina, Instituto de Ortopedia e Traumatologia, São Paulo, SP, Brazil.
}

\section{ABSTRACT}

The anterior cruciate ligament (ACL) is mostly responsible for providing knee stability. ACL injury has a marked effect on daily activities, causing pain, dysfunction, and elevated healthcare costs. $A C L$ reconstruction (ACLR) is the standard treatment for this injury. However, despite good results, ACLR is associated with a significant rate of failure. In this context, the mechanical and biological causes must be considered. From a biological perspective, the ACLR depends on the osseointegration of the graft in the adjacent bone and the process of intra-articular ligamentization for good results. Here, we discuss the mechanisms underlying the normal graft healing process after ACLR and its biological modulation, thus, presenting novel strategies for biological enhancements of the ACL graft. Level of evidence III, Systematic review of level III studies.

Keywords: Anterior Cruciate Ligament. Anterior Cruciate Ligament Reconstruction. Osseointegration. Orthopedics.

\section{RESUMO}

O ligamento cruzado anterior ( $L C A$ ) é um dos principais responsáveis pela estabilidade do joelho. Sua lesão gera importante prejuízo nas atividades diárias, causando dor e disfunção, com elevado custo socioeconômico. A reconstrução ligamentar é o tratamento padrão atual e, embora com bons resultados, ainda apresenta significativo índice de falhas. Nesse contexto, causas mecânicas e biológicas são consideradas. Do ponto de vista biológico, a reconstrução do LCA depende da osteointegração do enxerto no osso adjacente e do processo de ligamentização intra-articular para um bom resultado. Neste artigo, são discutidos o processo de cicatrização normal do enxerto após a reconstrução ligamentar e os mecanismos biológicos de modulação dessa cicatrização, apresentando as atuais estratégias biológicas já estudadas para otimizar esse processo. Nivel de evidência III, Revisão sistemática de estudos nível III.

Descritores: Ligamento Cruzado Anterior. Reconstrução do Ligamento Cruzado Anterior. Osseointegração. Ortopedia.

Citation: Leite CBG, Demange MK. Estratégias de tratamento biológico para cirurgia de reconstrução do ligamento cruzado anterior. Acta Ortop Bras. [online]. 2019;27(6):325-30. Available from URL: http://www.scielo.br/aob.

\section{INTRODUCTION}

The anterior cruciate ligament (ACL) is important for knee stability being a primary passive restrictor of anterior tibial translation and contributes to the rotational stability in different plane. ${ }^{1}$ Movements such as jumping or sidecutting manouvers are particularly controlled by this ligament ${ }^{2}$ In this regard, articular instability caused by ACL injury leads to significant impairment in daily activities, especially in athletes or young active individuals.

Classically, ACL injury occurs after trauma in valgus and internal/ external rotation, during landing movement or abrupt changes of direction, usually in non-contact conditions (without direct knee contact) ${ }^{2}$ In addition to instability caused by ACL injury, the evolution to early osteoarthrosis represents an important concern in long-term prognosis. ${ }^{1,3}$ Currently, more than 200,000 cases of ACL tears are estimated annually in the United States leading to high socioeconomic losses. ${ }^{4,5}$ Despite the different proposed treatment options given to the patient, $A C L$ reconstruction has remained the gold standard to treat $A C L$ injury. ${ }^{6,7}$ In fact, $A C L$ reconstruction is recommended in
$60-90 \%$ cases of injury. ${ }^{5}$ Among the different materials used as the neoligament, autografts often lead to better results when compared to artificial ligaments or allografts., 5

The sports return is an important indicator to evaluate the success of ACL reconstruction. ${ }^{8}$ According to a meta-analysis study, one in three patients did not returned to their pre-injury activity level and $45 \%$ did not successful return to sport in a competitive level. ${ }^{8}$ Despite the performance in sports, satisfactory results range from 75 to $97 \%$ of the patients. However, less favorable outcomes may occur in up to $25 \%$ of cases, depending on the assessment methods. ${ }^{9}$ Failures in $\mathrm{ACL}$ reconstruction are characterized by patient inability to return to routine activities or absence of knee stability. ${ }^{7}$ The main clinical signs and symptoms observed in cases of failure are joint instability, persistent edema and chronic pain. ${ }^{7}$ Therefore, mechanical and biological factors are evaluated to better understand the failure reason and obtain better functional results.

The mechanical factors include choice of graft, inaccuracies in graft harvest, inappropriate methods of fixation and errors in the

All authors declare no potential conflict of interest related to this article.

The study was conducted at the Instituto de Ortopedia e Traumatologia do Hospital das Clínicas, da Faculdade de Medicina - Universidade de São Paulo. Correspondence: Chilan Bou Ghosson Leite. Rua Ovídeo Pires de Campos, 333 - Cerqueira Cesar, São Paulo, SP, Brazil. 05403-10. chilanleite@gmail.com 
bone tunnels positioning. The femoral tunnel malpositioning is the major cause of failure in ACL reconstruction. 9,10 Inadequate graft position may lead to loss of knee motion, graft impingment and higher rate of re-rupture..$^{10}$ In addition, other anatomical alterations such as tibial slope increase, ${ }^{11}$ malignment of lower limb and other associated lesions (not diagnosed or not adequately treated) can also increase graft mechanical stress. ${ }^{12}$ In fact, LaPrade et al (1999) showed a higher force exerted on the ACL graft when there is concomitant posterolateral corner lesions, ${ }^{13}$ leading to procedure impairment. In addition to mechanical factors an adequate biological response should also occur. ${ }^{14}$ Biological factors related to failure include the intrusion of the synovial fluid after ACL injury and necrosis during graft hasvesting and bone drilling. ${ }^{9}$ Moreover, unfavorable mechanical and biological factors can induce the release of inflammatory cytokines by macrophages, sinoviocytes or fibroblasts - activating osteoclasts - and stimulate the production of metalloproteinases (MMPs) causing degradation of extracellular matrix (ECM) components. ${ }^{9}$

The native ACL attaches in the bone through both direct and indirect insertions being a complex highly specialized structure capable of transmitting mechanical loads from a soft tissue to the bone. ${ }^{15}$ The direct insertion of ACL consists in 4 morphological zones gradually transitioning the ligament to the cartilage and the bone. 6,15,16 The composition of the ECM of direct ligament insertion relates directly to the mechanical demand in the ligament-bone interface. ${ }^{17}$ The compressive strength that occurs especially in the insertion sites of the ligament leads to the production of molecules that compose the cartilage. ${ }^{17}$ Proteoglycans (inluding glycosaminoglycans - GAGs), agrecans and binding proteins are examples of ECM molecules of entheses that are increased during compression. ${ }^{18}$ Moreover, an enrichment of chondroitin 6 sulfate, instead of chondroitin 4 sulfate, is observed in the fibrocartilage during increased compression. ${ }^{16}$ Other components of the direct ACL insertion include cartilage-specific collagens, such as type II, IX, X and XI. Collagen $X$ is especially important to maintain the interface between the non-mineralized and mineralized portion of the fibrocartilage. The indirect insertion of ACL occurs through the Sharpey fibers, which anchor the ligament to the adjacent bone, providing additional mechanical resistance. ${ }^{15}$

After ACL reconstruction, the native ligament structure cannot be restored due to the absence of fibrocartilage remodeling at the graft-bone interface. ${ }^{15,19}$ In this case, instead of forming the 4 gradual zones, tissue incorporation occurs through a fibrovascular scar tissue layer, ${ }^{15,20}$ in which the osteointegration process of the graft is initiated. ${ }^{20}$ Progressive mineralization of the interface occurs, with subsequent bone ingrowth and graft incorporation. Finally, the continuum of collagen fibers is restored leading to the reformation of the ligament-bone junction. ${ }^{15}$

In order to improve the results after ACL reconstruction a growing number of evidences suggest that the enhancement of biological process is beneficial in graft healing. The different histological origins of ACL makes the graft incorporation in the bone a complex and slow healing process divided in osteointegration and intra-articular ligamentization. ${ }^{6,21}$ Different strategies to improve ACL healing have been studied in basic orthopedic science such as the use of mesenchymas cells, platelet-rich plasma (PRP), gene therapies, biophysical and pharmacological actions. ${ }^{6}$

Here, we are going to review the mechanisms of ACL healing process after ligament reconstruction describing some of biological modulation mechanisms and the alternatives existing to improve it results. The scientific understanding of the mechanisms involved in ligament reconstruction favors the development and implementation of new technologies focusing on the improvement of clinical outcomes.

\section{ACL healing process}

The graft healing process after ACL reconstruction involves three phases: early healing phase, proliferative phase and ligamentization phase. ${ }^{21}$ The early healing phase comprises the period up to the $4^{\text {th }}$ postoperative week and it is initially marked by hypocellularity and increased necrosis, mainly in the center of the graft. ${ }^{7}$ Here, the inflammatory responses triggered in the site of injury is characterized by the release of cytokines and chemokines that leads to the production of growth factors culminating to the migration and proliferation of cells, revascularization and synthesis of ECM components. ${ }^{22}$ In addition to pro-inflammatory cytokines, reactive oxygen species (ROS) are also modulators of cell recruitment. ${ }^{23}$ The tissue remodeling also starts during the early phase between the $1^{\text {st }}$ and $2^{\text {nd }}$ week with the influx of neutrophils and macrophages in the periphery of the graft. ${ }^{22}$

Approximately 4 weeks after graft implantation, the proliferative phase starts with the infiltration of cells derived from the synovial fluid, the native ACL remnant or from bone marrow elements released during bone tunnels drilling. ${ }^{21,24}$ The mechanical properties of the graft decreases until the $6^{\text {th }}$ postoperative week and is potentially associated to breakage of collagen fibers of the graft. ${ }^{21}$ The proliferative phase is characterized by maximum cellular activity and alterations of ECM. ${ }^{21}$ This phase is defined as the period between 4 and 12 weeks after surgery. ${ }^{25}$ The cellularity increases progressively with cell clusters observed mainly in the periphery of the graft and acellular areas in the middle. These hypercellular areas are formed by mesenchymal cells and fibroblasts, which secrete different growth factors, ${ }^{7}$ as bFGF, TGF-beta, PDGF. ${ }^{21}$ At the end of this phase, cellularity decreases progressively, but still remains high in comparison to the native ACL. ${ }^{21}$ During this period, a large number of myofibroblasts are observed, which are capable of exerting isometric tension in the cellular and extracellular environment. In intact ACL, these cells are responsible for the crimping structure of the collagen fibers. ${ }^{26}$ The number of myofibroblasts progressively increases during the first 3 months postoperatively and are responsible for restoring the tension required for the next process of ligamentization. ${ }^{21}$ Interestingly, although the number of myofibroblasts is considerable during recovery, the cell invasion is lower than in the normal tendon. ${ }^{27}$

In response to hypoxia during avascular necrosis in the early healing phase, there is an increase in VEGF expression, with consequent intense revascularization. ${ }^{7}$ This process, as in cellular infiltration, runs from the periphery to the entire graft. ${ }^{26}$ The increase in vascularization and extracellular infiltrate reduces the mechanical capacity of the tissue. Thus, it is considered that the graft has the lower mechanical properties in 6 to 8 weeks after reconstruction. In addition, there is a reduction in the density of large diameter collagen fibrils which are predominant in the native $\mathrm{ACL}$, which are progressively replaced by small diameter fibrils, ${ }^{21}$ whose mechanical strength is lower. ${ }^{28}$ The lack of the mechanical strength in the neoligament is also justified by the increase in type III collagen concentration. ${ }^{26}$

Most of the knowledge gathered regarding ACL healing is based on animal models. In humans, the remodeling process is likely to be more discreet and prolonged. In this regard, the complete replacement of intrinsic graft cells is not observed, and the central necrosis and denervation are smaller, not exceeding 30\% of the graft's thickness. In addition, the neovascularization process in humans is not so prominent when compared to experimental models. ${ }^{21,26}$

Lastly, the maturation or ligamentization phase starts 3 months after the graft implantation. ${ }^{26}$ This phase involves the progressive transformation of the graft in order to restore the native characteristics of the ligament. However, the complete restoration of $\mathrm{ACL}$ characteristics is controversial. Here, the progressive return to normal tissue cellularity takes place until the $6^{\text {th }}$ postoperative 
month. ${ }^{21}$ Similarly, ECM proteins and collagen crosslink values also tend to normalize in this period. ${ }^{26}$ The graft vascularization decreases, and the normal distribution of vessels occurs up to 12 months after the surgery. However, some changes remain. The diameter of the collagen fibrils remains heterogeneous and the regular crimp of the collagen does not return completely. ${ }^{25}$ The increased synthesis of collagen type III decreases during the ligamentization phase in comparison to the proliferative phase, but still remains in higher concentration than in native $A C L .{ }^{26} \mathrm{An}$ experimental study in goats showed that the concentration of type III collagen returns to baseline values only 3 years after graft implantation, suggesting that the ligamentization phase might be active throughout this long period. ${ }^{29}$

While the proliferation phase has differences between animals and humans, the ligamentization phase seems to be very similar. Distinction exists only in the period of time which the changes occur. ${ }^{26}$ Bone maturation occurs simultaneously with remodeling of the intra-articular portion. Several studies have shown that after 12 weeks the transition zone between the graft and the bone tunnel becomes more organized with an increase in the density of Sharpey fibers. ${ }^{21,26}$

\section{Biological mechanisms for modulation of healing}

As mentioned before, modulation of healing mechanisms favors a better outcome after ACL reconstruction. Although the weakest portion of graft rupture is in the intrasubstance (intra-articular) portion, the major investigation is directed towards the healing of the tendon-bone interface. ${ }^{14}$ Strategies to modulate this response have been pointed out as promising and involves: osteointegration in the tendon-bone interface, cell supplementation, osteogenesis, angiogenesis and modulation the inflammatory process. ${ }^{6,14,22,26}$

The ligamentous healing process should be balanced in order to ensure an efficient integration of the graft without compromising the intra-articular mechanical strength. In this sense, the induction of angiogenesis is essential to favor the survival and integration of graft into the bone, but when in excess can lead to weakness, decreasing the mechanical properties. ${ }^{14}$ In addition, the inflammatory response and production of matrix degradative enzymes are essential for the healing process, but when exacerbated may increase ligament deterioration in the intra-articular environment. ${ }^{14}$ Of note, the impact of non-steroidal anti-inflammatory drugs (NSAIDs) in tendon/ligament repair is still poorly known. ${ }^{30}$ The use of NSAIDs is efficient in control the pain specially in the initial postoperative period, however it is difficult to assume the routine use by surgeons, since local inflammation should be regulated but not inhibited. ${ }^{14}$ The use of biological therapies to modulate the healing process in the $A C L$ reconstruction has been increasingly explored due to its promising potential to favor a better outcome in the postoperative period. In the next sections we are going to explore the recent findings on biological enhancement strategies for ACL reconstruction.

\section{Growth factors}

Growth factors are molecules biologically involved in cell proliferation, differentiation, migration and adhesion. They are produced and secreted by different types of tissues, and are crucial orchestrators of tissue repair processes, acting in all phases of healing. ${ }^{31}$

Several studies have evidenced a positive association between the administration of exogenous growth factors with the improvement of ligamentous healing, acting both in the process of osteointegration and ligamentization. ${ }^{6}$

Among the different factors, BMP, bFGF, ${ }^{32}$ EGF, TGF-beta and VEGF are the most studied. The platelet concentrate, that are formed by different growth factors, such as PDGF, TGF-BETA and VEGF is also well described in literature being a potential approach for enhancement of the healing process. ${ }^{24}$
In clinical studies, the most commonly used strategy is the treatment with platelet-rich plasma (PRP), derived from autologous blood. PRP is a source of several growth factors and other bioactive molecules, which can active transcription factors after binding to specific receptors increasing expression of growth-related and immunomodulatory genes. During ACL reconstruction, PRP favors the ligamentization process while has a lower impact in bone-graft integration. ${ }^{33}$

\section{Gene Therapy}

Gene therapy is designed to introduce genetic modifications into joint cells to induce the production of beneficial molecules for specific treatment proposals. ${ }^{34}$

The transfection of BMP-2 gene into different cells in the graft, and the consequent increase in BMP-2 expression, significantly increases the integration of the semitendinosus graft into the bone tunnel. ${ }^{35}$ Along with this study, others have shown the beneficial impact of transfection of growth factors'genes during healing. In this context, gene therapy can optimize the supply of growth factors in the integration site. Modulating stem cells with growth factors, such as BMP, TGF-beta and PDGF-B, a continuous concentration of these factors is released at the graft-tunnel interface. ${ }^{6}$ Therefore, there would be a continuous, larger and more controlled supply of these substances. Importantly, the use of these factors is limited due to its low half-life, typically varying from minutes to hours. In addition, gene therapy still finds some resistance due to the potential risk for malignancy and exaggerated release of cytokines. ${ }^{36}$

\section{Biomaterials}

Biomaterials are composed by inert molecules that interact with the patient biological system without causing immunological rejection. ${ }^{37}$ Examples of biomaterials include chitin fabrics, ${ }^{38}$ bioglass, ${ }^{39}$ hyaluronic acid $^{14}$ and collagen matrix ${ }^{6}$.

Biomaterials are implanted in the human body functioning as biological fixation and coating methods, biosynthetic bone substitutes or osteoconductive materials. The biodegradable orthopedic devices favors modulation of the inflammatory response, regulation of the ECM formation, angiogenesis stimulation, osteoblastic proliferation and differentiation and accelerates the mineralization process improving the bone formation. ${ }^{38-40}$

In particular, biosynthetic bone substitutes, such as the demineralized bone matrix, are promising materials for $A C L$ reconstruction due to its osteoinductive and osteoconductive properties. ${ }^{6}$ Osteoinduction is the process by which osteogenesis is induced, implying the recruitment and stimulation of immature cells to become osteoblasts precursors. Osteoconduction is the capability to allow bone growth over its surface..$^{41}$ Osteoconductive materials, such as calcium phosphate, showed good results related to improvement the osteointegration process. ${ }^{42}$

\section{Multi and pluripotent cells}

Stem cells, multi or pluripotent, are defined as cells capable of long-term proliferation, self-renewal and differentiation into many cell lineages and types. ${ }^{34}$ Examples are: induced pluripotent cells (iPSCs), umbilical cord-derived mesenchymal stem cell, ${ }^{6}$ stem cells derived from fat (ADSCS), bone marrow (BMSCs) ${ }^{43}$ or from tendons and ligaments (derived from ACL CD34 +). ${ }^{44}$ Usually, these cells are placed on scaffolds for their stocking and release.

The use of multipotent cells stimulates the formation of a native-like fibrocartilage in the graft-bone interface ${ }^{45}$ due to its osteogenic, chondrogenic and/or adipogenic potential. ${ }^{44}$ Stem cells can removed through aspiration of blood from the bone marrow during the $A C L$ reconstruction or be cultivated and expanded prior to the surgical procedure. ${ }^{6}$ The advantage of autologous cells is to avoid the risk of rejection, infection or malignization. ${ }^{46}$ The so-called 
mesenchymal stem cells are multipotent cells with the ability to differentiate into mesoderm adult cells, ${ }^{34}$ such as the periosteum. ${ }^{15}$ In this context, the use of periosteum-derived stem cells can recreate the fibrocartilage present in the normal ACL insertion through the promotion of osteogenesis and chondrogenesis. ${ }^{43}$ In fact, good results were found when synthetic grafts covered by periosteum were used in ligament reconstruction. ${ }^{40}$ Interestingly, the presence of the ACL-remained mesenchymal cells was beneficial in favoring the proprioception and vascularization of the graft enhancing the healing process. ${ }^{47}$

\section{Pharmacological strategies}

Pharmacological strategies to enhance ACL healing include the use of agonists or antagonists that modulate the different phases of the repair process, namely: bone growth or bone resorption, inflammatory response and degradative enzymes present after ACL injury, and during the postsurgical healing period. Metalloproteinases (MMPs) inhibitors, which reduce the MMPs in the synovial fluid, improving the maturity of the graft-bone interface ${ }^{48}$ are one example of pharmacological treatment.

In addition, agonists of the parathyroid hormone $(\mathrm{PTH})$ receptor 1 have been suggested to improve reconstruction outcome. PTH is an anabolic regulator of calcium and phosphorus homeostasis, acting on the osteocytes and chondrocytes via PTH receptor (PTH1R). This is the only PTH receptor present in the bone tissue, being expressed in the stem cells derived from the bone marrow (BMSCs), osteoblasts and osteocytes. In the early phase of the ligament osteointegration process, $\mathrm{PTH}$ binds to the receptor present in these cells, balancing the bone turnover process, preventing osteoblastic apoptotic and stimulating bone formation. Thus, accelerates the heal during osteointegration. ${ }^{49}$

Drugs primarily described for different purposes, may also be beneficial. Simvastatin, a drug commonly used to treat dyslipidemia, has both anti-inflammatory and antioxidant effects decreasing inflammatory mediators (such as TNF-alpha and INF-gamma) and oxygen free radicals. ${ }^{50}$ Moreover, Simvastatin showed an anabolic effect on the bone formation inducing BMP-2 culminating with angiogenesis and osteogenesis in the early stages after ACL reconstruction. However, without improves the long-term biomechanical properties. ${ }^{15}$

Bisphosphonates are drugs used in the treatment of diseases affecting bone metabolism. It has high affinity for hydroxyapatite, the main component of inorganic bone matrix, and act directly or indirectly by osteoclasts inhibition, interfering in bone remodeling with increased bone mass and improvement of mineralization. Bisphosphonates also act through inhibition of inflammatory mediators. ${ }^{51}$ The use of alendronate, one type of bisphosphonates, reduces the tunnel bone resorption and promotes osteointegration of the graft during the early phases of the healing process. ${ }^{52}$

\section{Biophysical measures}

Other strategies were also studied and proved to be effective in enhancing the healing process after ACL reconstruction. Hyperbaric Oxygen Therapy promotes a better organization of collagen fibers. Moreover, it optimizes neovascularization, ${ }^{53}$ inducing the expression of angiopoetin, bFGF and VEGF and accelerates the osteoinduction via BMP-2, ${ }^{54}$ leading to a higher maximal pullout strength. ${ }^{53}$

The use of low intensity pulsed ultrasound (LIPUS) ${ }^{48,55}$ and extracorporeal shockwave therapy (ESWT) proved to be effective in improving the healing process acting in both molecular and biomechanical aspects. ${ }^{6}$ LIPUS can stimulate osteoblasts and fibrocytes and align collagen fibers. In addition, it increases the expression of angiogenic factors, such as VEGF. ${ }^{55}$ ESWT proved to be effective in bone formation via BMP and neovascularization. ${ }^{56}$ It is suggested that the shock waves may influence the mechanotransduction in the tissue, which is the ability of biological modulation through physical stimuli, converting acoustic mechanical energy into biological signals. ${ }^{57}$ Thus, it induces the production of angiogenic factors such as VEGF and endothelial nitric oxide synthase (eNOS), leading to cell proliferation and formation of neovessels. ${ }^{57}$ Indeed, a clinical study showed reduction in tibial tunnel bone loss in the group that received the ESWT treatment compared to the control group, two years after ACL reconstruction. ${ }^{56}$

Bioactive molecules

Lastly, the use of bioactive molecules has also been studied in $A C L$ reconstruction. The addition of vitamin $\mathrm{C}$ (ascorbic acid) in the intraoperative irrigation prevented graft deterioration, restoring the anteroposterior stability of the knee in the $6^{\text {th }}$ week after surgery. ${ }^{23}$ Ascorbic acid acts as an antioxidant, neutralizing ROS and antagonizing the oxidative stress caused by the inflammatory process. ${ }^{23}$ By modulating the cell recruitment, it reduces graft degeneration improving bone, tendon and graft healing process. ${ }^{58}$

Vitamin $\mathrm{D}$ is essential for mineralization and consequently for the maintenance of bone quality, with an important role in skeletal homeostasis. During the consolidation process it acts on the inflammatory cells, cytokines, growth factors, osteoblasts and osteoclasts. ${ }^{59}$ Although no study has evaluated the direct effect of vitamin D during the healing process after ACL reconstruction, it is expected that by improving mineralization, vitamin D may optimize graft osteointegration.

Another bioactive molecule that is potentially beneficial during ACL healing is omega- 3 fatty acid family. Omega- 3 lipids act as an antioxidant and anti-inflammatory, leading to good results during the healing of the medial collateral ligament. In this regard, studies that address the direct effect of omega- 3 derived molecules are needed to better understand the mechanisms of repair induction. ${ }^{60}$

\section{CONCLUSION}

Anterior cruciate ligament injury is one of the major causes of knee surgery and, despite the satisfactory results, ACL reconstruction can lead to joint instability and early osteoarthritis. In recent years, the increasing number of surgeries and the on-demand need for good results explain the growing amount of technological investment in the field. Among the different aspects of ACL reconstruction that may be modulated, the graft healing process is an interesting therapeutic target. Given that the biological mechanisms involved in $\mathrm{ACL}$ healing are being appreciated in literature, new focused therapies are beginning to emerge. In the present study, we discussed the natural pathway of graft integration and healing in order to explore the major biological regulatory mechanisms that enhance graft repair. Despite the several studies and controversies regarding ACL healing, the mechanisms that explain different outcomes are not completely described hindering the development of new opportunities for treatment. The restoration of the native condition of osteotendinous insertion is still challenging and more research is needed to clarify the pathophysiology of ACL injury and healing leading to a more guided and intelligent design of new therapies.

Here we presented different biological strategies to enhance neoligament repair. Each type of management has specific advantages and disadvantages; therefore, the treatment choice must be based on patient needs and medical history. Timing, treatment schedule and the dose of different treatments are still controversial and further studies will shed light on the impact of biological enhancements for $A C L$ reconstruction. In this regard, surgical management of $A C L$ injury may be followed by adjunctive biological therapies that will decrease failure rates, leading to a better/faster functional recovery and patient return to usual activities. 
AUTHORS' CONTRIBUTIONS: Each author contributed individually and significantly to the development of this article. CBGL (0000-0002-8386-3121) contributed to the intellectual concept, writing and review of the article; MKD (0000-0003-1999-9478) contributed to the design of this work and review of the article. ${ }^{*} \mathrm{ORCID}$ (Open Researcher and Contributor ID).

\section{REFERENCES}

1. Kiapour AM, Murray MM. Basic science of anterior cruciate ligament injury and repair. Bone Joint Res. 2014;3(2):20-31.

2. Lam M-H, Fong DT, Yung PS, Ho EP, Chan WY, Chan KM. Knee stability assessment on anterior cruciate ligament injury: Clinical and biomechanical approaches. Sports Med Arthrosc Rehabil Ther Technol. 2009;1(1):20.

3. Lattermann C, Jacobs CA, Proffitt Bunnell M, Huston LJ, Gammon LG, Johnson $\mathrm{DL}$, et al. A multicenter study of early anti-inflammatory treatment in patients with acute anterior cruciate ligament tear. Am J Sports Med. 2017;45(2):325-33.

4. Hofbauer M, Muller B, Murawski CD, van Eck CF, Fu FH. The concept of individualized anatomic anterior cruciate ligament $(A C L)$ reconstruction. Knee Surg Sports Traumatol Arthrosc. 2014;22(5):979-86.

5. Sochacki KR, McCulloch PC, Lintner DM, Harris JD. Hamstring autograft versus hybrid graft in anterior cruciate ligament reconstruction: a systematic review of comparative studies. Arthroscopy. 2019;35(6):1905-13.

6. Hexter AT, Thangarajah T, Blunn G, Haddad FS. Biological augmentation of graft healing in anterior cruciate ligament reconstruction: a systematic review. Bone Joint J. 2018;100-B(3):271-84

7. Ménétrey J, Duthon VB, Laumonier T, Fritschy D. "Biological failure" of the anterior cruciate ligament graft. Knee Surg Sports Traumatol Arthrosc. 2008;16(3):224-31.

8. Ardern CL, Taylor NF, Feller JA, Webster KE. Fifty-five per cent return to competitive sport following anterior cruciate ligament reconstruction surgery: an updated systematic review and meta-analysis including aspects of physical functioning and contextual factors. Br J Sports Med. 2014;48(21):1543-52.

9. Lui $\mathrm{P}$, Zhang $\mathrm{P}$, Chan K, Qin L. Biology and augmentation of tendon-bone insertion repair. J Orthop Surg Res. 2010;5:59.

10. Celiktas M, Kose O, Sarpel Y, Gulsen M. Can we use intraoperative femoral tunnel length measurement as a clue for proper femoral tunnel placement on coronal plane during ACL reconstruction? Arch Orthop Trauma Surg. 2015;135(4):523-8.

11. Dejour $\mathrm{H}$, Bonnin $\mathrm{M}$. Tibial translation after anterior cruciate ligament rupture. Two radiological tests compared. J Bone Joint Surg Br. 1994;76(5):745-9.

12. LaPrade RF, Hamilton CD, Engebretsen L. Treatment or acute and chronic combined anterior cruciate ligament and posterolateral knee ligament injuries. Sports Med Arthrosc. 1997;5(2):91

13. LaPrade RF, Resig S, Wentorf F, Lewis JL. The effects of grade III posterolatera knee complex injuries on anterior cruciate ligament graft force. A biomechanical analysis. Am J Sports Med. 1999;27(4):469-75

14. Fu SC, Cheuk YC, Yung SH, Rolf CG, Chan KM. Systematic Review of Biological Modulation of Healing in Anterior Cruciate Ligament Reconstruction. Orthop J Sports Med. 2014;2(3):2325967114526687.

15. Chen $\mathrm{CH}$, Lee $\mathrm{CH}$. Biological fixation in anterior cruciate ligament surgery. Asia-Pacific Journal of Sports Medicine, Arthroscopy, Rehabilitation and Technology. 2014;1(2):48-53.

16. Benjamin M, Toumi H, Ralphs JR, Bydder G, Best TM, Milz S. Where tendons and ligaments meet bone: attachment sites ('entheses') in relation to exercise and/or mechanical load. J Anat. 2006;208(4):471-90.

17. Benjamin M, Kumai T, Milz S, Boszczyk BM, Boszczyk AA, Ralphs JR. The skeletal attachment of tendons--tendon "entheses." Comp Biochem Physiol A Mol Integr Physiol. 2002;133(4):931-45

18. Milz S, Benjamin M, Putz R. Molecular parameters indicating adaptation to mechanical stress in fibrous connective tissue. Adv Anat Embryol Cell Biol. 2005; 178:1-71.

19. Takayama K, Kuroda R. Biological Augmentation of Anterior Cruciate Ligament Grafts. Oper Tech Orthop. 2017;27(1):33-7.

20. Grana WA, Egle DM, Mahnken R, Goodhart CW. An analysis of autograft fixation after anterior cruciate ligament reconstruction in a rabbit model. Am J Sports Med. 1994;22(3):344-51.

21. Scheffler SU, Unterhauser FN, Weiler A. Graft remodeling and ligamentization after cruciate ligament reconstruction. Knee Surg Sports Traumatol Arthrosc. 2008;16(9):834-42.

22. Ekdahl M, Wang JH, Ronga M, Fu FH. Graft healing in anterior cruciate ligament reconstruction. Knee Surg Sports Traumatol Arthrosc. 2008;16(10):935-47.

23. Fu SC, Cheng WH, Cheuk YC, Mok TY, Rolf C, Yung SH, et al. Development of vitamin $\mathrm{C}$ irrigation saline to promote graft healing in anterior cruciate ligament reconstruction. Journal of Orthopaedic Translation. 2013;1(1):67-77.
24. Yoshikawa $\mathrm{T}$, Tohyama $\mathrm{H}$, Katsura $\mathrm{T}$, Kondo $\mathrm{E}$, Kotani $\mathrm{Y}$, Matsumoto $\mathrm{H}$, et al. Effects of local administration of vascular endothelial growth factor on mechanical characteristics of the semitendinosus tendon graft after anterior cruciate ligament reconstruction in sheep. Am J Sports Med. 2006;34(12):1918-25.

25. Janssen RPA, Scheffler SU. Intra-articular remodelling of hamstring tendon grafts after anterior cruciate ligament reconstruction. Knee Surg Sports Traumatol Arthrosc. 2014;22(9):2102-8.

26. Scheffler S, Becker R. Graft Remodeling and bony ingrowth after anterior cruciate ligament reconstruction. In: Doral MN, Karlsson J, editors. Sports injuries: prevention, diagnosis, treatment and rehabilitation. Berlin, Heidelberg: Springer Berlin Heidelberg; 2015. p. 1077-87.

27. Tohyama H, Yasuda K. Anterior Cruciate Ligament (ACL) Healing: ACL Graft Biology. Sports Med Arthrosc. 2005;13(3):156.

28. Frank C, McDonald D, Bray D, Bray R, Rangayyan R, Chimich D, et al. Collagen fibril diameters in the healing adult rabbit medial collateral ligament. Connect Tissue Res. 1992;27(4):251-63.

29. Ng GY, Oakes BW, Deacon OW, McLean ID, Eyre DR. Long-term study of the biochemistry and biomechanics of anterior cruciate ligament-patellar tendon autografts in goats. J Orthop Res. 1996;14(6):851-6.

30. Su B, O'Connor JP. NSAID therapy effects on healing of bone, tendon, and the enthesis. J Appl Physiol. 2013;115(6):892-9.

31. Dinh T, Braunagel S, Rosenblum BI. Growth factors in wound healing: the present and the future? Clin Podiatr Med Surg. 2015;32(1):109-19.

32. Gulotta LV, Rodeo SA. Biology of autograft and allograft healing in anterior cruciate ligament reconstruction. Clin Sports Med. 2007;26(4):509-24.

33. Andriolo L, Di Matteo B, Kon E, Filardo G, Venieri G, Marcacci M. PRP Augmentation for ACL Reconstruction. Biomed Res Int. 2015;2015:371746.

34. Demange MK, Sisto M, Rodeo S. Future trends for unicompartmental arthritis of the knee: injectables \& stem cells. Clin Sports Med. 2014;33(1):161-74.

35. Martinek V, Latterman C, Usas A, Abramowitch S, Woo SL, Fu FH, et al. Enhancement of tendon-bone integration of anterior cruciate ligament grafts with bone morphogenetic protein-2 gene transfer: a histological and biomechanical study. J Bone Joint Surg Am. 2002;84(7):1123-31.

36. Evans $\mathrm{CH}$, Ghivizzani SC, Robbins PD. Orthopedic gene therapy--lost in translation? J Cell Physiol. 2012;227(2):416-20.

37. Bhat S, Kumar A. Biomaterials and bioengineering tomorrow's healthcare Biomatter. 2013;3(3). pii: e24717.

38. Nomata H, Nakaishi M, Takakuda K. Enhanced biological fixation of ligaments to bone tissues utilizing chitin fabrics. J Biomed Mater Res. 2018;106(6):2355-60.

39. Jiang J, Wan F, Yang J, Hao W, Wang Y, Yao J, et al. Enhancement of osseointegration of polyethylene terephthalate artificial ligament by coating of silk fibroin and depositing of hydroxyapatite. Int J Nanomedicine. 2014;9:4569-80.

40. Dai Z, Bao W, Li S, Li H, Jiang J, Chen S. Enhancement of polyethylene terephthalate artificial ligament graft osseointegration using a periosteum patch in a goat model. Int J Sports Med. 2016;37(6):493-9.

41. Albrektsson T, Johansson C. Osteoinduction, osteoconduction and osseointegration. Eur Spine J. 2001;10 Suppl 2:S96-101.

42. Pan W, Wei Y, Zhou L, Li D. Comparative in vivo study of injectable biomaterials combined with BMP for enhancing tendon graft osteointegration for anterior cruciate ligament reconstruction. J Orthop Res. 2011;29(7):1015-21.

43. Karaoglu S, Celik C, Korkusuz P. The effects of bone marrow or periosteum on tendon-to-bone tunnel healing in a rabbit model. Knee Surg Sports Traumatol Arthrosc. 2009;17(2):170-8.

44. Takayama K, Kuroda R. Biological augmentation of anterior cruciate ligament grafts. Oper Tech Orthop. 2017;27(1):33-7.

45. Lim J-K, Hui J, Li L, Thambyah A, Goh J, Lee EH. Enhancement of tendon graft osteointegration using mesenchymal stem cells in a rabbit model of anterior cruciate ligament reconstruction. Arthroscopy. 2004;20(9):899-910.

46. Matsumoto T, Kubo S, Sasaki K, Kawakami Y, Oka S, Sasaki H, et al. Acceleration of tendon-bone healing of anterior cruciate ligament graft using autologous ruptured tissue. Am J Sports Med. 2012;40(6):1296-302.

47. Muneta T, Koga H. Anterior cruciate ligament remnant and its values for preservation. Asia Pac J Sports Med Arthrosc Rehabil Technol. 2017;7:1-9.

48. Steiner ME, Murray MM, Rodeo SA. Strategies to improve anterior cruciate ligament healing and graft placement. Am J Sports Med. 2008;36(1):176-89. 
49. Bi F, Shi Z, Jiang S, Guo P, Yan S. Intermittently administered parathyroid hormone [1-34] promotes tendon-bone healing in a rat model. Int J Mol Sci. 2014;15(10):17366-79.

50. Kim SW, Kang HJ, Jhon M, Kim JW, Lee JY, Walker AJ, et al. Statins and Inflammation: New Therapeutic Opportunities in Psychiatry. Front Psychiatry. 2019;10:103.

51. Cremers S, Papapoulos S. Pharmacology of bisphosphonates. Bone 2011;49(1):42-9.

52. Lui PP, Lee YW, Mok TY, Cheuk YC. Local administration of alendronate reduced peri-tunnel bone loss and promoted graft-bone tunnel healing with minimal systemic effect on bone in contralateral knee. J Orthop Res. 2013;31(12):1897-906.

53. Yeh WL, Lin SS, Yuan LJ, Lee K-, Lee MY, Ueng SW. Effects of hyperbaric oxygen treatment on tendon graft and tendon-bone integration in bone tunnel: biochemical and histological analysis in rabbits. J Orthop Res. 2007;25(5):636-45

54. Okubo Y, Bessho K, Fujimura K, Kusumoto K, Ogawa Y, lizuka T. Effect of hyperbaric oxygenation on bone induced by recombinant human bone morphogenetic protein-2. Br J Oral Maxillofac Surg. 2001;39(2):91-5.
55. Khanna A, Nelmes RT, Gougoulias N, Maffulli N, Gray J. The effects of LIPUS on soft-tissue healing: a review of literature. Br Med Bull. 2009;89:169-82.

56. Wang CJ, Ko JY, Chou WY, Hsu SL, Ko SF, Huang CC, et al. Shockwave therapy improves anterior cruciate ligament reconstruction. J Surg Res. 2014;188(1):110-8

57. Wang CJ, Wang FS, Yang KD, Weng LH, Hsu CC, Huang CS, et al. Shock wave therapy induces neovascularization at the tendon-bone junction. A study in rabbits. J Orthop Res. 2003;21(6):984-9.

58. DePhillipo NN, Aman ZS, Kennedy MI, Begley JP, Moatshe G, LaPrade RF. Efficacy of vitamin $\mathrm{C}$ supplementation on collagen synthesis and oxidative stress after musculoskeletal injuries: a systematic review. Orthop J Sports Med. 2018;6(10):2325967118804544.

59. Gorter EA, Hamdy NA, Appelman-Dijkstra NM, Schipper IB. The role of vitamin $D$ in human fracture healing: a systematic review of the literature. Bone. 2014;64:288-97.

60. Vidmar MF, Siqueira LO, Brito VB, Martins CA, Pimentel GL, Almeida CR, et al. Suplementação com ômega-3 pós-reconstrução do ligamento cruzado anterior. Rev Brasil Med Esporte. 2016;22(2):131-7. 